TAP CHÍ KHOA HỌC ĐẠI HỌC TÂN TRÀO

ISSN: $2354-1431$

http://tckh.daihoctantrao.edu.vn/

\title{
Đổi mới phương pháp dạy - học môn Lý luận chính trị ở các trường đại học hiện nay
}

\author{
Cung Thị Ngọ ${ }^{a^{*}}$ \\ ${ }^{a}$ Học viện Chinh trị Khu vục I, Học viện Chính trị Quốc gia Hồ Chỉ Minh \\ "Email:ngoccungthi@gmail.com
}

\section{Thông tin bài viết}

Ngày nhận bài:

24/9/2018

Ngày duyệt đăng:

$10 / 12 / 2018$

Tù khoá:

Đổi mói; phuơng pháp dạyhoc; lý luận chính trị; tụ hoc; hoc nhóm; hoc hiện truờng.

\begin{abstract}
Tóm tắt
Việc khắc phục những bất cập trong công tác giáo dục đào tạo để chuyển biến mạnh mẽ từ việc chủ yếu truyền thụ tri thức sang việc hình thành, củng cố phẩm chất, năng lực cho người học đáp ứng yêu cầu của nhiệm vụ xây dựng và bảo vệ Tổ Quốc Việt Nam là một đòi hỏi tất yếu đối với sự nghiệp giáo dục đào tạo hiện nay. Tình trạng ngại, kém hứng thú học tập môn Lý luận chính trị của sinh viên ở các trường đại học hiện nay đang diễn ra khá phổ biến. Để khắc phục tình trạng này, cả người học và người dạy đều phải cùng thay đổi nhiều mặt để xác định được phương pháp dạy - học phù hợp. Cần có sự đổi mới mạnh mẽ trong phương pháp dạy - học để chuyển từ mục tiêu truyền thụ tri thức là chủ yếu sang mục đích phát triển ở người học năng lực học tập chủ động và giải quyết vấn đề của thực tiễn. Bài viết này, đề cập đến một số vấn đề mà người dạy và người học cần thay đổi để xác định được tâm thế, phương pháp, hình thức dạy - học môn Lý luận chính trị đúng đắn, phù hợp trong giai đoạn hiện nay.
\end{abstract}

\section{Mở đầu}

Sinh thời, Hồ Chí Minh luôn coi trọng công tác giáo dục và coi đó là sự nghiệp vĩ đại - sự nghiệp trồng người. Người dạy rằng, việc cốt yếu sự nghiệp ấy là người thầy dạy sao cho thiết thực, hiệu quả tránh dông dài, người học thì phải có hiểu biết tốt (học tốt) mới có thực hành tốt (làm tốt). Người phê phán bệnh nói dông dài, thiếu thiết thực: "Nói mênh mông trời đất. Nói gì cũng có. Nhưng chỉ chừa một điều không nói đến là những việc thiết thực cho địa phương đó, những việc mà dân chúng ở đó cần biết, cần hiểu, cần làm, thì không nói đến" [1, tr.343]. Người đặc biệt coi trọng việc học tập và thực hành lý luận chính trị. Nhưng học tập lý luận chính trị như thế nào cho hiệu quả, có ích lợi. Hồ Chí Minh đã từng căn dặn, học tập lý luận cần tránh rơi vào hình thức, sáo rỗng, đừng biến mình thành cái bồ đựng sách di động hoặc bụng đầy chữ nghĩa nhưng làm vẫn theo kinh nghiệm, thiếu sâu sát với thực tế. Học phải đi đôi với hành, lý luận gắn với thực tiễn. "Lý luận rất cần thiết nhưng nếu cách học tập không đúng thì sẽ không có kết quả. Do đó, trong lúc học tập lý luận chúng ta cần nhấn mạnh: lý luận phải liên hệ với thực tế'[2, tr.496]. Vậy hiện nay để dạy - học tốt môn lý luận chính trị ở các trường đại học, cần chú ý những vấn đề gì?

\section{Nội dung}

2.1. Mô hình dạy - học môn Lý luận chính trị ở các trường Đại học ${ }^{* *}$ hiện nay

Môn Lý luận chính trị được giảng dạy trong các trường đại học khối không chuyên ngành nghĩa Mác-

\footnotetext{
** Các trường Đại học của Việt Nam có sử dụng chương trình các môn lý luận chính trị dành cho sinh viên đại học, cao đẳng khối không chuyên ngành nghĩa Mác- Lênin, tư tưởng Hồ Chí Minh do Bộ Giáo dục và đào tạo ban hành
} 
Lênin, tư tưởng Hồ Chí Minh hiện nay gồm 3 phân môn: Nhũng nguyên lý co bản của Chủ nghĩa MácLênin, Tu tuơơng Hồ Chí Minh và Đuờng lối cách mạng của Đảng Cộng sản Việt Nam. Mục tiêu của môn học nhằm: 1 . Trang bị thức lý luận chính trị cơ bản về Chủ nghĩa Mác- Lênin, tư tưởng Hồ Chí Minh và đường lối cách mạng của Đảng Cộng sản Việt Nam 2. Xác lập thế giới quan duy vật biện chứng; nhân sinh quan cách mạng; hình thành, củng cố năng lực tư duy khoa học; 3 . Hình thành, củng cố, phát triển phương pháp nhận thức và làm việc khoa học.

Để phù hợp với đối tượng và thực hiện được mục tiêu môn học, các trường Đại học đang thực hiện mô hình dạy - học tích cực - lấy người học làm trung tâm. Theo mô hình này, người học được đặt ở vị trí trung tâm của quá trình đào tạo, vừa là mục đích lại vừa là chủ thể của quá trình đào tạo. Mục tiêu chủ yếu của toàn bộ quá trình đào tạo là hướng tới nhu cầu, khả năng, lợi ích của người học với mục đích phát triển ở người học kỹ năng và năng lực độc lập trong học tập, nghiên cứu và giải quyết vấn đề của thực tế. Vai trò của người dạy là tạo ra những tình huống để phát triển vấn đề, giúp người học nhận biết vấn đề, lập luận giả thuyết, làm sáng tỏ và thử nghiệm các giả thuyết đồng thời rút ra kết luận cần thiết để bổ sung tri thức và củng cố kỹ năng của mình.

Để thực hiện mô hình này, về phía đội ngũ giảng viên, nhiều chương trình đã được triển khai nhằm bổ sung, hoàn thiện, chia sẻ kiến thức chuyên môn, nghiệp vụ sư phạm, tạo động lực, môi trường thuận lợi cho việc thực hành đổi mới phương pháp giảng dạy theo mô hình lấy người học làm trung tâm. Về phía sinh viên, các trường Đại học cũng đã có những hướng dẫn, điều chỉnh, thay đổi quy định đào tạo hướng người học đến tâm thế, động cơ và phương pháp học tập phù hợp nhằm biến quá trình đào tạo thành quá trình tự đào tạo.

Dạy - học theo mô hình này, bước đầu đã đem lại những sự thay đổi tích cực cho cả 2 phía: người dạy đã nhận rõ và thực thi việc đổi mới phương pháp giảng dạy hướng tới yêu cầu chuẩn đầu ra của môn học, người học đã tích cực, tự giác hơn trong học tập, nghiên cứu. Những tín hiệu khả quan của mô hình dạy - học tích cực đã rõ, tuy nhiên trong việc học tập các môn lý luận chính trị vẫn còn hiện tượng học tập thiếu tích cực, tự giác, kém liên hệ với thực tiễn, coi môn học này là môn "khó nhai", “ miễn qua là được” ở một bộ phận đáng kể sinh viên. Để khắc phục tình trạng này và tiếp tục phát huy mô hình học tập tích cực, cần chú ý tới những vấn đề sau đây.

\subsection{Một số vấn đề trong đổi mới phương pháp} dạy - học

\section{Về tâm thế học tập của nguời học}

Thư nhất, người học cần nhận thức lại mục đích và xác định được động cơ, thái độ học tập môn học. Có thể thấy, vẫn còn một bộ phận không nhỏ sinh viên coi việc học tập môn này là việc phải trải qua trong quá trình học tập chứ chưa xác định được ý nghĩa của môn học đối với việc hình thành phẩm chất nền tảng và phát triển năng lực của bản thân. Nói cách khác, việc học tập môn lý luận chính trị không thực sự xuất phát từ nhu cầu, mong muốn của học sinh, sinh viên. Và điều đó là một trong những nguyên nhân chủ yếu đã dẫn đến tình trạng học tập hình thức, thiếu thực chất, thiếu động lực. Để thay đổi điều này, thì một trong những biện pháp hữu hiệu là thiết kế cho sinh viên "sân chơi" (chương trình) phù hợp để tạo tâm thế học tập đúng đắn. Ở đó, sinh viên có thể chia sẻ, giãi bày tâm tư, ước muốn về khóa học, về cuộc sống tương lai, về lý tưởng, mơ ước, hiểu biết về môn học... và đội ngũ giảng viên có thể thông qua đó khai thác những vấn đề thực tế và thực hiện mục tiêu môn học. Những chương trình đã được tổ chức như: Chuoong trình SV, Rung chuông vàng, Hội thi các môn học lý luận chính trị, Sinh viên nói về mình... đã mang lại nhiều hiệu ứng tích cực.

Thư hai, về phía nhà trường, cần hướng dẫn, dành đủ thời gian và tạo môi trường thuận lợi cho việc học tích cực. Cần có đề cương chi tiết môn học, nguồn học liệu đầy đủ, cơ sở vật chất thiết yếu (thư viện thông minh, phòng học đa năng, phòng nhóm...) Giảng viên cần kích hoạt, chia sẻ phương pháp, cảm hứng học tập nghiên cứu để kích thích họ tự "lấp đầy" những ham muốn tri thức và dần tự hoàn thiện kỹ năng tư duy giải quyết vấn đề.

Cần quản lý một cách hiệu quả thời gian tự học. Một trong những cách quản lý hiệu quả là quản lý qua sản phẩm tự học. Sản phẩm tự học không nên nặng về số lượng trang dòng mà nên khuyến khích sản phẩm chứa ý tưởng mới, phát hiện mới, phân tích sáng tạo và đề xuất giải pháp phù hợp. Và hình thức của sản phẩm cũng nên đa dạng: bút ký (viết tay hoặc đánh máy hoặc tệp Slide, phóng sự...) theo cá nhân hoặc nhóm học tập. Những phần bút ký hay, tốt nên được phổ biến, truyền tải trên Website. Việc bình chọn do sinh viên thực hiện dưới sự giám sát, thẩm định của giảng viên chuyên môn của môn học. Sản phẩm tự học cần phải chiếm tỷ phần thích hợp trong đánh giá chuyên cần, kết quả của học viên. 
Thứ $b a$, cần chuyển biến mạnh mẽ từ cách học thụ động sang cách học tích cực. Cách học tập thụ động là cách học làm theo sự dẫn dắt, yêu cầu đơn tuyến của giảng viên trong các khâu, các bước truyền tải nội dung của quá trình dạy - học và sự chủ động, tích cực của người học bị hạn chế. Bản chất của cách học chủ động đó là phát huy vai trò chủ thể tích cực của người học trong mọi hoạt động học. Người học được chủ động tìm kiếm, khám phá, trải nghiệm và thẩm thấu tri thức. Muốn vậy, người học cần chủ động xây dựng một kế hoạch học tập môn học một cách khoa học, hợp lý. Với đề cương chi tiết môn học đã được công bố, sinh viên có thể chủ động xác định vấn đề học tập gắn với từng nội dung. Để làm được việc này thì giáo trình, tài liệu học tập và sự hướng dẫn của giảng viên sẽ là những điều kiện thiết yếu.

Chẳng hạn, trong môn học " Nhũng nguyên lý co bản của chủ nghĩa Mác - Lênin”, vấn đề học tập có thể là:

[1]. Nhũng yếu tố cấu thành và lôgic tu tuoongchủ nghĩa Mác - Lênin.

[2]. Giá trị của chủ nghĩa Mác - Lênin trong thòi đại ngày nay là gì.

[3]. Nội dung các nguyên tắc phương pháp luận biện chứng duy vật.

[4]. Vận dưng các nguyên tắc phuoong pháp luận biện chứng duy vật nhu thế nào cho đúng trong học tập, nghiên cưu và trong cuộc sống.

[5]. Tại sao Đảng cộng sản Việt Nam lưa chọn chủ nghĩa Mác- Lênin, tu tưởng Hồ Chí Minh làm nền tảng tu tương, làm kim chỉ nam cho hành động cách mang.

[6]. Hiện nay giai cấp công nhân Việt Nam đang tăng nhanh về số luợng, tuy nhiên về chất luợng còn nhiều hạn chế, bất cập: trình độ khoa học, công nghệ, $\dot{y}$ thíc tổ chức kỷ luạt, $\dot{y}$ thức chinh trị, hiểu biết pháp luật, tác phong công nghiệp... Vậy các biện pháp để đảm bảo và phát huy vai trò lãnh đạo của giai cấp công nhân trong giai đoạn hiện nay là gì.

[7]. Đảng Cộng sản Việt Nam khẳng định kinh tế tu nhân là một động lục quan trọng trong phát triển kinh tế - xã hội. Nhu vậy, có phải là đề cao khuyến khích tu hũu, gia tăng yếu tố chệch huoóng xã hội chủ nghĩa hay không?...[3]

Khi câu hỏi học tập đã được xác định, người học cần tích cực, chủ động trong tìm tòi chiếm lĩnh tri thức. Trong mỗi giờ học lý thuyết, thảo luận hay tự học, sinh viên cần tích cực tư duy để giải quyết các vấn đề đã đặt ra. Các câu hỏi trong hoạt động tư duy cần có là: Vì sao, như thế nào, vận dụng ra sao và bất cập giữa lý luận và thực tiễn là gì?.. Cần tránh và khắc phục tâm lý học tập tự ty, thụ động, hình thức để từng bước xác lập và củng cố kỹ năng của tư duy lý luận.

\section{Về hình thức tổ chức học tập}

Nếu hình thức học tập đơn điệu sẽ dẫn đến sự nhàm chán và dẫn tới suy kiệt động lực học tập. Vì vậy, việc đa dạng hình thức tổ chức học tập là một yêu cầu bắt buộc trong học chủ động. Các hình thức có thể là:

\section{Một là, học tập tại giảng đường}

Hình thức này là hình thức phổ biến trong học tập lý luận chính trị hiện nay. Uu điểm của hình thức tổ chức này ở chỗ: ổn định về mặt không gian, thời gian; không khí, môi trường sư phạm được duy trì trong suốt tiết học. Điều này khiến cho sự tập trung chú ý, sự suy nghĩ tốt hơn và dẫn đến việc đạt mục tiêu học tập cũng dễ dàng hơn. Tuy nhiên, nhược điểm của nó lại là do không gian lớp học ổn định không thay đổi và việc phải duy trì một tư thế quá lâu cũng dễ dẫn đến những ức chế tâm lý và gây ra những hiệu ứng tiêu cực. Vì vậy, để phát huy ư điểm và hạn chế nhược điểm của tiết học lý thuyết, cần phải tổ chức tiết học một cách khoa học, sử dụng linh hoạt nhiều phương pháp để tăng hoạt động tương tác giữa các chủ thể trong giờ học tạo ra hiệu ứng tích cực. Đặc biệt, trong tiết giảng lý thuyết, giảng viên cần khắc phục lối thuyết trình độc thoại, một chiều cần lồng ghép nhiều phương pháp giảng dạy, dùng nhiều thủ pháp sư phạm để kích thích sự suy nghĩ, thu hút sự tập trung của sinh viên, động viên họ thường xuyên liên hệ với thực tế.

Một điều dễ nhận thấy, khi nghe thuyết trình, sinh viên thường nghe thụ động, tính tích cực chủ động bị hạn chế. Nếu chỉ nghe thụ động, người học sẽ rất nhanh quên và như vậy rất khó để đạt đến bậc thông hiểu và vận dụng tri thức vào thực tiễn. Vì vậy, dạy - học qua tình huống có vấn đề (có thể là tình huống thực tế hoặc là giả định) là một sự lựa chọn hợp lý, hiệu quả. Qua tình huống được đặt ra, người học được tham gia, trải nghiệm và được dẫn dắt làm rõ cơ sở lý thuyết và thực tiễn. Cách dạy- học này giúp cho các chủ thể hiểu bản chất của vấn đề, hoạt hóa khả năng liên hệ với thực tế và kích thích sự chủ động chiếm lĩnh tri thức và thúc đẩy khả năng vận dụng lý luận vào thực tiễn. [4]

Trong thảo luận, giảng viên cần linh hoạt đa dạng các hình thức phân nhóm, nội dung thảo luận gắn với chuyên đề. Để học chủ động học, sinh viên cần tích cực 
thực hiện tốt nhiệm vụ được phân công trong nhóm, liên kết trao đổi với những thành viên trong nhóm để giải đáp và nắm vững nội dung chủ đề của nhóm cũng như những câu hỏi và tính huống học tập do bản thân đặt ra. Cần tránh phân nhóm theo một tiêu chí hành chính (theo lớp học niên chế, hoặc theo khoa ...) và buổi thảo luận nào cũng lặp lại như thế. Điều này có thể sẽ gây ra tâm thế nhàm chán, sẽ xuất hiện trưởng nhóm đương nhiên (tổ trưởng) và báo cáo viên chuyên trách (do được tín nhiệm cao). Vì vậy, phân nhóm trong tiết thảo luận cũng cần sự linh hoạt, đa dạng. Nên chăng với những tình huống thảo luận cần sự phân tích chuyên sâu cần phân nhóm theo các tiêu chí chuyên ngành (sư phạm, kỹ thuật, nghiệp vụ quan hệ công chúng...); với những tình huống gợi mở, đang cần nhiều ý kiến phân tích, phản biện cần phân nhóm ngẫu nhiên (theo tên, sở thích, sinh nhật...).

\section{Hai là, học tập hiện trường, thực địa}

Hình thức học hiện trường ở hệ đào tạo đại học cũng gần giống như việc học thực hành, trải nghiệm thực tế trong môi trường thực tế của các cấp học phổ thông. Chẳng hạn, học sinh học nghề bậc phổ thông trung học (nghề đầu bếp, cắm hoa, may, gốm...) sẽ được vào bếp, vào xưởng để thực hành thì sinh viên chuyên ngành sẽ không có gì tốt hơn khi họ được học tập trong môi trường thực tế mà họ sẽ phải thao tác trong nghề nghiệp tương lai.

Tuy nhiên, để giờ học tại hiện trường hiệu quả cần:

- Lựa chọn được nội dung học tập phù hợp: Nội dung học hiện trường tốt nhất đó chính là những nội dung trong từng môn học đang có sự mâu thuẫn giữa lý luận và thực tiễn hoặc giữa chính sách đang còn hiệu lực và thực tế đang vận hành. Những vấn đề này sẽ có thể thể hiện một cách rõ ràng, sinh động trong thực địa hiện trường nhưng lại khó khăn hơn để thể hiện, mô tả nơi giảng đường. Chẳng hạn, trong môn Nguyên lý, có nội dung: Quy luật sản xuất phải phù hợp với trình độ của lực luợng sản xuất trong phần chủ nghĩa duy vật lịch sủ. Để cho sinh viên hiểu được những biểu hiện của việc phù hợp hay không phù hợp của quan hệ sản xuất (mặt quan hệ sở hữu) với trình độ của lực lượng sản xuất (đòi hỏi về trình độ, mức độ tập trung của công cụ, phương tiện, đối tượng sản xuất), nếu tổ chức cho họ học tại một công ty sản xuất tập trung quy mô lớn, ứng dụng công nghệ cao thì sẽ đạt được những hiệu quả tốt hơn nơi giảng đường. Tuy nhiên, việc học tại hiện truoòng thưc tế đòi hỏi có sự chi phí cao hơn về kinh phí và thời gian so với học tại giảng đường tập trung. Điều này là chưa phù hợp với thực tế và điều kiện hện có của nhiều cơ sở đào tạo đại học. Vì vậy, công nghệ thực tế ảo sẽ giúp việc học hiện truoòng ảo giảm chi phí mà hiệu ứng cũng không thua kém. Để thiết lập được kho dữ liệu hiện trường ảo đòi hỏi các nhà giáo dục phải sưu tầm, thiết kế thậm chí dàn dựng công phu (tuy nhiên dữ liệu này có thể dùng nhiều lần, với nhiều nội dung học tập khác nhau). Đây là khâu thiết yếu mà ngành giáo dục cần đầu tư để bắt nhịp với công nghệ giáo dục 4.0.

- Tính điển hình của hiện trường cũng là nhân tố quyết định tới hiệu quả học tập. Nếu lựa chọn được hiện trường điển hình thì những vấn đề, tình huống học tập sẽ bộc lộ rõ hơn và việc nhận thức của sinh viên cũng dễ dàng và sâu sắc hơn. Ngược lại, nếu hiện trường không mang tính điển hình (hoặc tính đại diện không cao) thì các khía cạnh của tình huống học tập sẽ không được bộc lộ đầy đủ và điều này ảnh hưởng rất lớn đến hiệu quả của học tập.

Ba là, tổ chức tự học

Trong biển kiến thức mênh mông của thời đại bùng nổ tri thức và công nghệ thông tin, thế độc quyền tri thức bị gỡ bỏ, thời đại của cơ sở dữ liệu dùng chung như nguồn tài nguyên toàn cầu đã xác lập. Vì vậy, thích ứng với đặc điểm ấy của thời đại thì mỗi chủ thể nhận thức cần phải xác định tự chiếm lĩnh, tự tìm kiếm tri thức cho bản thân sẽ là xu thế chủ yếu. Do lẽ đó mà việc tự học tập, tự bồi dưỡng đó là một đặc trưng cần thiết phải có cho mọi chủ thể nhận thức và hành động hiện nay. Vậy tổ chức tự học như thế nào để đạt hiệu quả?

Về phía cá nhân mỗi sinh viên cần phải tổ chức một cách khoa học, hợp lý quỹ thời gian học tập, lượng thời gian tự học tương xứng, hài hòa với thời gian học có hướng dẫn. Điều quan trọng trong tự học, tự nghiên cứu là phát hiện, phân tích và giải quyết được những tình huống có vấn đề về mặt lý luận và thực tiễn. Tình huống có vấn đề phải tiềm chứa những xung đột giữa lý luận và thực tiễn hoặc giữa chính sách đang còn hiệu lực và thực tế của cuộc sống đang diễn ra. Cần tránh kiểu tự học kiểu "tự kỷ"- một mình chiêm nghiệm, dùi mài lý luận hàn lâm mà cần kết hợp linh hoạt giữa học một mình và theo nhóm. Học một mình, việc tập trung sẽ giúp ta đào sâu suy nghĩ, tập trung vào những vấn đề trọng tâm thích hợp cho việc hệ thống, tổng kết. Học theo nhóm (trao đổi) thích hợp với việc bàn luận, phản biện những vấn đề chưa thống nhất. Những cuộc tranh luận trong nhóm sẽ là thức ăn bổ ích cho những ý tưởng, những phát hiện mới về nhận thức và giải pháp mới cho thực tiễn mà việc tự học một mình khó đạt 
được. Những vấn đề tranh luận nhóm nên được đẩy đến tận cùng và nếu vướng mắc cần phải tìm chuyên gia trợ giúp. Cần tránh việc bỏ lửng, tranh luận không đến nơi, đến chốn sẽ dẫn đến tình trạng mơ hồ trong nhận thức và rối rắm trong tư duy.

Cần chủ động kết nhóm trong học tập. Nguyên tăc kết nhóm học tập đó là có cùng mối quan tâm, cùng có những ý tưởng, mong muốn... Hiện nay, cùng với hình thức gặp gỡ trực tiếp trong nhóm thì mạng xã hội đang có những ứng dụng vượt trội trong kết nhóm. Thành tựu công nghệ này giúp các nhóm học tập tăng cường trao đổi, chia sẻ thông tin, tri thức một cách hữu hiệu

\section{Kết luận}

Như vậy để có thể học tập tích cực thì sự nỗ lực học tập một cách chủ động, sáng tạo của mỗi sinh viên sẽ là nhân tố mang tính quyết định. Để đạt được mục tiêu học tập buộc người học cần phải có động cơ, mục đích học tập đúng đắn, một phương pháp học tập khoa học, hiện đại, xa rời cách học tập hình thức, thụ động, nặng về tri thức lý luận thiếu liên hệ với thực tế, cuộc sống; người dạy phải có sự đổi mới mạnh mẽ trong phương pháp giảng dạy với sự hỗ trợ của các phương tiện dạy học hiện đại và với một chương trình, nội dung khoa học, phù hợp, liên môn và liên thông đáp ứng được yêu cầu của thực tiễn.
Đổi mới là một quá trình biện chứng bao chứa cả thành công và những thất bại đợi chờ. Nhưng chúng ta không thể cầu toàn mà ngại thay đổi bởi đó là mệnh lệnh của cuộc sống cho sự nghiệp giáo dục đào tạo nước nhà. Thay đổi phương pháp chiếm lĩnh tri thức, nêu cao tinh thần tự học, tự bồi dưỡng nhằm nâng cao khả năng tư duy lý luận, năng lực thực tiễn, tinh thần nhân văn, đạo đức để thực hiện lập thân, lập nghiệp, kiến quốc đó là trí tuệ, bản lĩnh, trách nhiệm của mỗi chúng ta - những trí thức xã hội chủ nghĩa Việt Nam trong cách mạng 4.0.

\section{TÀI LIỆU THAM KHẢO}

[1] Hồ Chí Minh (2011), Toàn tập, tập 5, Nxb. Chính trị Quốc gia - Sự thật, Hà Nội.

[2[ Hồ Chí Minh (1996), Toàn tập, tập 8, Nxb. Chính trị Quốc gia, Hà Nội.

[3] Bộ giáo dục và đào tạo (2018), Giáo trình nhũng nguyên lý co bản của chủ nghĩa Mác - Lênin (dành cho sinh viên đại học, cao đẳng khối không chuyên ngành nghĩa Mác- Lênin, tư tưởng Hồ Chí Minh), Xuất bản lần thứ 11, Nxb Chính trị quốc gia - Sự thật, Hà Nội.

[4] Vũ Ngọc Am (2009), Một số vấn đề về phuơng pháp giảng dạy lý luận chính trị, Nxb Thông tấn, Hà Nội.

\section{Innovating the teaching - studying method of political theory subjects at universities these days}

Cung Thi Ngoc

\section{Article info}

Recieved:

24/9/2018

Accepted:

10/12/2018

Keywords:

Innovation; teaching and learning method; political theory, self-study, groupstudy, farmer field school.

\begin{abstract}
Overcoming inadequacies in education and training to create a turning point from imparting knowledge to building and consolidating qualities and capacities for learners to meet the requirements of constructing and defending the Vietnamese Fatherland is an indispensable requirement for the current education and training career. The situation of hesitation and lack of interest is now quite common in studying political theory subjects among students at universities. To overcome this situation, both learners and teachers have to change different aspects to identify an appropriate teaching and learning method. The method of teaching and learning needs strong innovation to change from the goal of imparting knowledge to the main purpose of developing the ability to actively learn and solve problems in reality of learners. This article refers to some issues that teachers and learners need to change in order to determine the appropriate method and forms of teaching adn learing political theory subjects in the current period.
\end{abstract}

